\title{
Construction of Traceability System for Quality Safety of Cereal and Oil Products
}

\author{
Huoguo Zheng ${ }^{1,2, *}$, Shihong $\mathrm{Liu}^{1,2}$, Hong Meng ${ }^{1,2}$, and Haiyan $\mathrm{Hu}^{1,2}$ \\ ${ }^{1}$ Agricultural Information Institute, Chinese Academy of Agricultural Sciences, \\ Beijing, P.R. China 100081, \\ Tel.: +86-10-82106263; Fax: +86-10-82106263 \\ huoguos@caas.net.cn
}

${ }^{2}$ Key Laboratory of Digital Agricultural Early-warning Technology, Ministry of Agriculture, The People's Republic of China, Beijing, P.R. China 100081

\begin{abstract}
After several significant food safety incident, global food industry and governments in many countries are putting increasing emphasis on establishment of food traceability systems. Food traceability has become an effective way in food quality and safety management. The traceability system for quality safety of cereal and oil products was designed and implemented with HACCP and FMECA method, encoding, information processing, and hardware R\&D technology etc, according to the whole supply chain of cereal and oil products. Results indicated that the system provide not only the management in origin, processing, circulating and consuming for enterprise, but also tracing service for customers and supervisor by means of telephone, internet, SMS, touch machine and mobile terminal.
\end{abstract}

Keywords: traceability system, quality and safety, cereal and oil products, traceability encoding.

\section{Introduction}

Food traceability system, also called food tracking and tracing system, has become an effective way in food safety management. After several food safety related issues, particularly several food sandals, the global food industry and governments in many countries have paid increasing attention to systems along the food chain (Liu Yin. 2003). The implementation of traceability systems is important: one is to give consumers the right to know, and the second is to strengthen the responsibility for the enterprises which produce food products, the third is to find the root causes when the food safety issue emerged (Pu Yinyan. 2008).

Traceability system was initially promoted by the EU to control the risks of mad cow disease in 1997. From then on, most agriculture developed countries are active to implement food.safety traceability systems, but they have different focus.In June 2002, the Canadian federal government established an ambitious goal that, before 2008, the

\footnotetext{
* Corresponding author.
} 
country would achieve tracing back 80 percent of agricultural products to its source, supporting the "Brand Canada strategy"(Lu Changhua et al.. 2007), of which a mandatory identification system for cattle and beef on July 1, 2002 came into operation. In December 2003, the United States developed the statutes of tracking food safety, which required all enterprises involved in food transportation, distribution and import recording their trade information for tracking and tracing back (Cheng Hao. 2007). In July 2003, The EU published a White Paper on Food Safety, proposing a new framework for food safety system. Most countries in the EU have implemented mandatory livestock and meat products traceability system (Zhu Haipeng. 2007). The Japanese Government has passed new legislations on cattle and beef requiring a mandatory traceability system from farm to retail (Wang Lifang et al. 2005). The system allows consumers via the Internet to enter identification numbers of beef on the packaging box getting access to production information of the beef. Australia has plans for general mandatory traceability. NLIS is currently carrying out, which enables trace backward and forward from farm-of-origin to abattoir (Schroeder et al. 2005).

China has also achieved important progress in food tracing. In April 2004, the State Food and Drug Administration and 7 other departments chose meat industry as a pilot industry, started meat and meat products traceability institution construction and system implementation (General Administration of Quality Supervision. 2002). In June 2004, Administration of national barcode management promoting investigated on vegetable products traceability and started an application project on two vegetable production bases located in Shouguang and Luocheng respectively in Shandong province (Zhou Yingheng et al., 2002). Shanghai Livestock Bureau legislated to build digital archives for pigs, cattle, sheep and other critters, and the residents can now get access to the egg production information through internet (Shanghai agricultural committee. 2001). In August 2008, Beijing enforced a food traceability system along the full supply chain for the food supplied for Olympic games to secure food quality and safety (Chang Xiang. 2007).

Cereal and oil products are the common agricultural products in our country, therefore, construct the traceability system for cereal and oil products of great significance. Food traceability system can trace the quality and safety information from "farm to table "(Liu Shihong. 2008). To construct the traceability system, we should study and analyses the critical quality safety point basic the whole supply chain of cereal and oil products, then carry out the research of key technologies and build the traceability system for cereal and oil products.

\section{Traceability System Design}

\subsection{System Architecture Design}

Aiming at the major quality problems of cereal and oil products existing in the production (cultivation), inspection, storage, processing, circulation and other links, this paper starts with systematical analysis of the source, channel and the kind of contamination, which forms the traceability system framework. In this paper, integrated with the information flow analysis, FMECA (Failure Mode Effect and Criticality Analysis) (Kang Ri. 2006) approach is used as a tool to detect the possible critical 
control points. HACCP (Bao Dayue. 2007) (Hazard Analysis and Critical Control Point) quality system and some related national standards on cereal and oil products are referred to determine the key quality indicators in the supply chain. Then, the traceability framework and an optimal set of quality indicators come into appearance. At the same time, study the key technology and design the coding principle. Finally, construct the traceability system for cereal and oil products.

The traceability system for cereal and oil products, which will not only meet the day-to-day management and internal tracing needs, but also provide services for consumer and regulatory by means of SMS, telephone, network and mobile portable-terminal., has achieved origin, processing, detecting, quality and safety management and other functions. From another perspective, the system can be broken down into three layers: information collection, information processing, and information services. The main function of the level of information collection include filtering the key factors in the quality and safety indexes, acquisition the information about origin, processing, producing, quality inspection, logistics and sales, supporting the ultimate tracing. Information processing level's role is building the tracing platform through information encoding technique, information collection, information exchange and hardware R\&D technology. We provide different kinds of services for consumers and regulators through SMS, telephone, network platform and mobile terminals. The diagram of system architecture is shown in Figure 1.
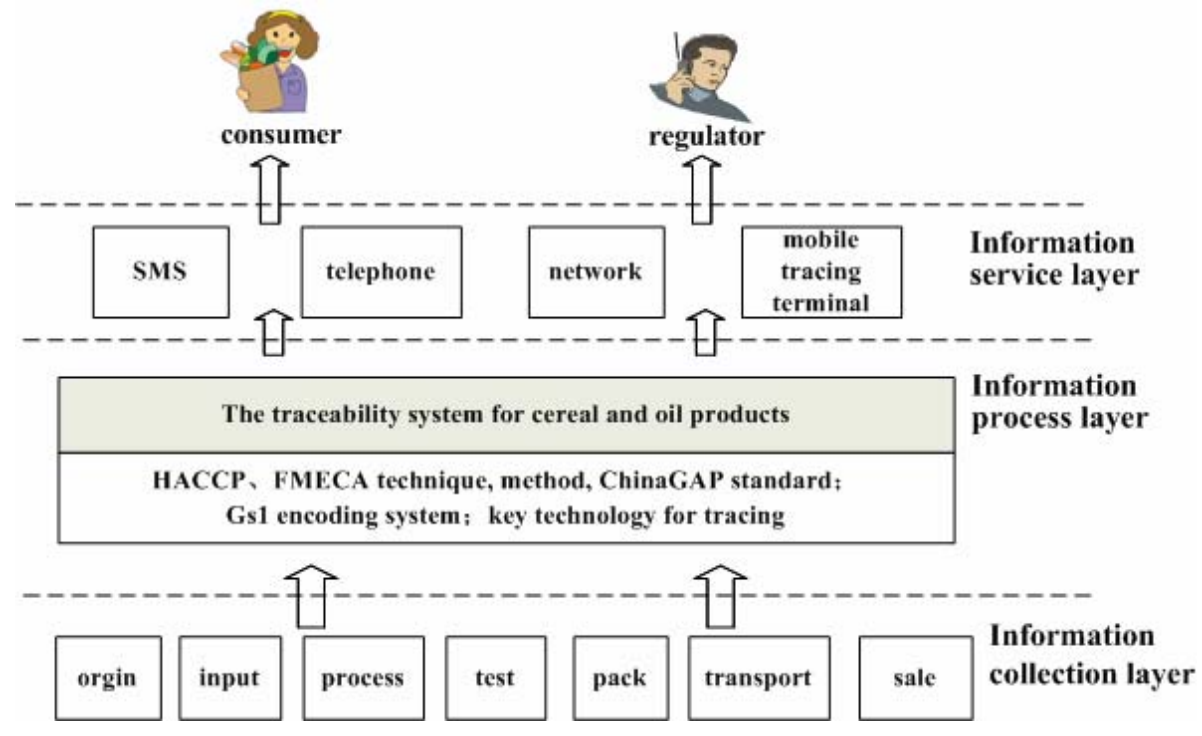

Fig. 1. System architecture diagram for cereal and oil products tracing

\subsection{Function Design for the System}

The traceability system for cereal and oil products consists of four sub-systems: origin management system, production control system, indexes management system and tracing management. The origin system achieves the information management of 
natural environment of origin, input materials, producing process based on the China GAP standard. Production control system management is the foundation of the whole system, which cover the information from raw material purchase to final product sale. The indexes management system's main function is to determine the critical quality and safety factors of the cereal and oil products, after that, management them. The tracing management system is the display layer of the system, which provides services for users by a wide range of interface.

\section{Key Technologies}

\subsection{Traceability Encoding}

Unified encode system is the premise of cereal and oil products traceability, is also the basis of information exchanging and processing. The encoding system should comply with the following principles: uniqueness, stability, commonality, expandability and applicability.

\section{1 origin code design}

Origin code is the key to get the quality and safety information of the raw materials planting stage of the cereal and oil products, is also the core code for the tracing. Considering the commonality and the standardization of the origin code, we adopt the 《Rules for Coding of Agricultural Land》 standard, which was published in Dec 1, 2007. The origin code is composed of 5 parts. The code structure is shown in Fig 2.

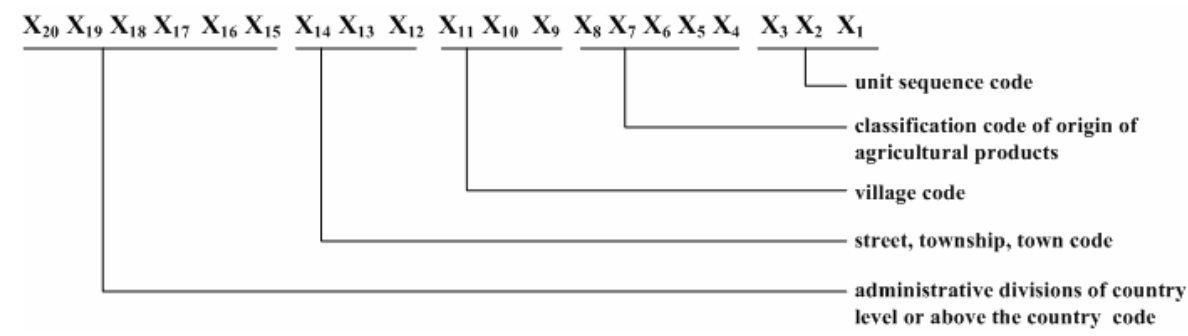

Fig. 2. Origin coding rules for cereal and oil products

\section{Traceability code design}

The traceability code is the unique identification of cereal and oil products. All of the quality and safety information of the products can be obtained through this code, combined with the production control system. This code is from commodity code, but contains more information than commodity code. Compared to the animal products, fruits products, vegetables products and other agricultural products, cereal and oil products have long production chain and involved many factors, which can't identification individual as animal products, can't identification producer of raw materials as fruits and vegetables products (Yang Xinitin et al., 2007).

The traceability code follows the UCC/EAN-128 standard (Lin Ling et al., 2004), which is a worldwide standard for exchanging data between different companies. We put forward a unique identification number for encode the data concerning cereal and 
oil products. The identification number consists of five parts, including enterprise identification number, commodity identification number, batch number and two kinds of verifying number. The first three items in fact form the Global Trade Item Number (short for GTIN). The code structure and example for cereal and oil products is shown in Fig.3.
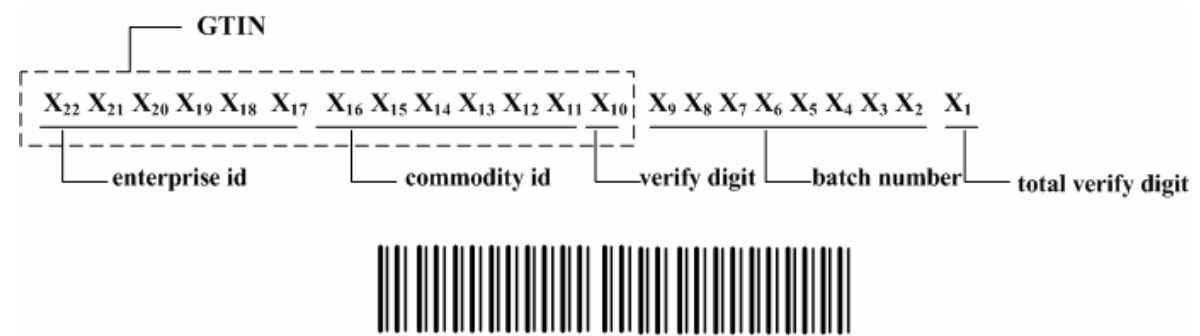

(01) 6901234600046 (10) 200804148

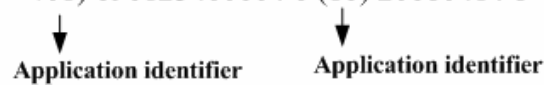

Fig. 3. The code structure and barcode example

\subsection{Multi-platform Tracing Technology}

The tracing management system can provide different services for three kinds of user such as consumers, enterprise managers and supervisors, through five patterns including SMS, telephone, computer, fixed terminals in the supermarket and mobile terminal. The system locate at the data center, which preserve the whole information of supply chain. The diagram of multi-platform is shown in Fig 4.

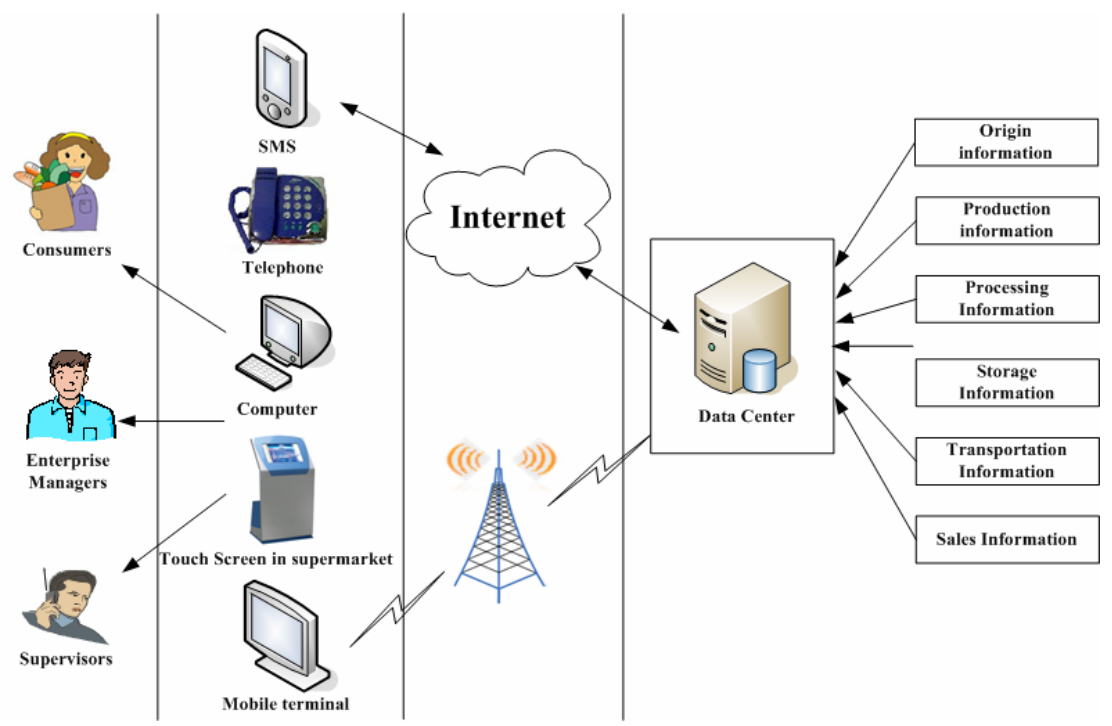

Fig. 4. The diagram of multi-platform tracing 


\subsection{Mobile Terminal R\&D Based on GPRS Network}

Since the wireless application widely spread and for the consumers convenience, we developed a kind of mobile electronic terminal based on GPRS data transmission, which was consisted of three important parts: the motherboard, GPRS communication module and a micro Liquid-crystal display (short for LCD). The main board is used for processing information, while the GPRS communication module used for receive the information and send the results back. The micro LCD is simply for displaying the results in a friendly way. The mobile terminal is shown in Fig.5.

The mobile terminal can trace the cereal and oil products under the condition of absence of cable networks, to facilitate regulatory agencies at any time, anywhere to monitor the quality of agricultural products. It is also applicable to other agricultural products tracing.
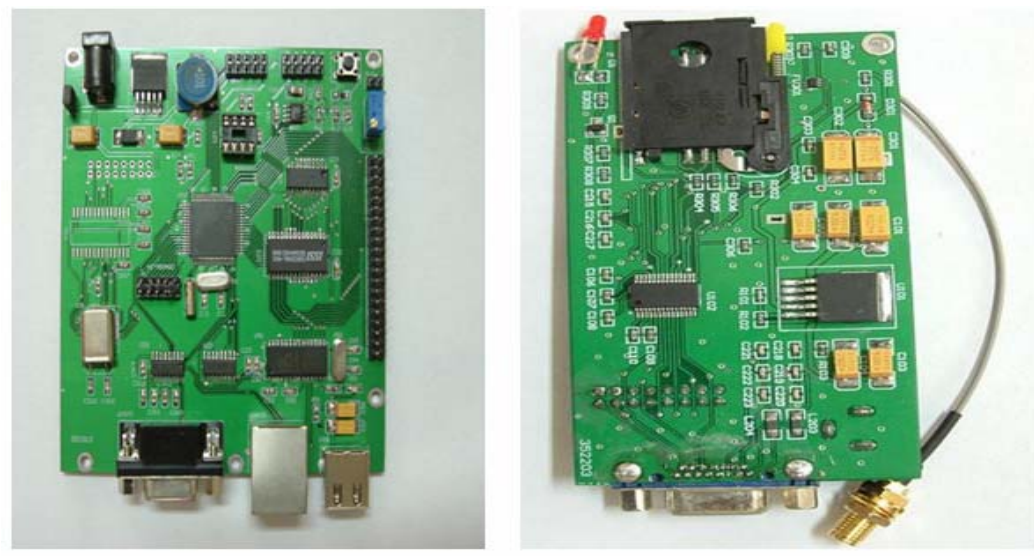

Fig. 5. The diagram of the hardware of the mobile terminal

\section{Conclusion and Discussions}

The traceability system for cereal and oil products, which was implemented by using the .net framework, RBAC (Role-Based Access Control) method, component technology, has been used in supermarket for comsumers. In china, cereal and oil products take a large account in agriculture products. Quality management for cereal and oil product has an overall significance. The methodology, application system and the pilot project of traceability systems for cereal and oil products would help the related enterprises to establish traceability systems and rebuild the consumer confidence of Chinese food products, also can promote the enforcement of the food safety law of agricultural products in a practical way. However, the precise information of the whole food chain is another critical factor for the traceability system.

\section{Acknowledgements}

Funding for this research was provided by National High Technology Research and Development Program of China called as "863" (2006AA10Z268). 


\section{References}

Dayue, B.: Guide to implementation of HACCP. Chemical Industry Press (2007)

Schroeder, C.T., Tonsorb, T.G.: Australia'S Live-stock Identification Systems: Implications for United States Programs [EB/OL], http: / / www.agmanager.info/events/risk_profit/2004/Schroeder (April 27, 2005)

Xiang, C.: The food quality and safety traceability systems for Beijing Olympic games will be put into use in August, http: / /www. chinanews. com.cn / (July 09, 2007)

Hao, C.: Animal product safety control and traceability technologies. Modern Agriculture science and technology (13), 169-170 (2007)

Hongping, F., Zhongze, F., Ling, Y., Aisheng, R.: Appliance and Discussion of Traceability System in Food Chain. Ecological Economy 17(4), 30-33 (2007)

Schwagele, F.: Traceability from a European perspective. Meat Science (71), 164-173 (2005)

General Administration of Quality Supervision, Inspection and Quarantine of the People's Republic of China. GB/T 15425-2002 (2002)

Ri, K.: FMECA approach and its application. National Defense Industry Press (2006)

Ling, L., Deyi, Z.: On the Construction of Food Quality and Safety Traceability System. Commercial research (21) (2005)

Opara, L.U.: Traceability in agriculture and food supply chain: A review of basic concepts, technological implications and future prospects. Food, Agriculture \& Environment 1(1), 101-106 (2003)

Shihong, L., Huoguo, Z., Meng, et al.: Study of full-supply-chain quality and safety traceability systems for cereal and oil products. IFIP. Springer, USA (2008)

Yin, L., Licheng, C.: Traceability Production System of Beef in EU and USA. Food science (8), 182-185 (2003)

Changhua, L., Changjiang, W., Sinong, H., et al.: Identification and Traceability System for Animals and Animal Products, pp. 35-36. Chinese Agricultural Science and Technology Press (2007)

Massimo, B., Maurizio, B., Roberto, M.: FMECA approach to product traceability in the food industry. Food Control 17(9), 137-145 (2004)

Yinyan, P.: Construction of traceability system for quality safety of apple and apple juice. Transactions of the Chinese society of agricultural engineering 24(2), 289-292 (2008)

Shanghai agricultural committee. Notification in carrying out animal identification in Shanghai. Shanghai agricultural committee (126), August 24 (2001)

Lifang, W., Changhua, L., Jufang, X., Yinong, H.: Review of traceability system for domestic animals and livestock products. Transactions of the Chinese Society of Agricultural Engineering (07) (2005)

Wenying, X.: The Policy of Traceability in Quality and Safety of Agricultural Products in USA. World Agriculture (04) (2006)

Jin, X.: Agricultural product supply chain—Guarantee food safety. China Logistics \& Purchasing (07) (2005)

Xintin, Y., Chuanheng, S., Jianpin, Q., et al.: Application of UCC/EAN-128 bar code technology in agricultural product safety traceability system. Computer engineering and applications 43(1) (2007) 
Hui, Y., Yufa, A.: Theoretical discussion of implementation Traceability System in food supply chain. Agricultural Quality and Standards (03) (2005)

Gumin, Z., Gongyu, C.: Food safety and Traceability System. China Logistics \& Purchasing (14) (2005)

Yingheng, Z., Xianhui, G.: Application of Traceability in Food Safety. Research of Agricultural Modernization (06) (2002)

Haipeng, Z.: Research and implementation on traceability system of key cereal enterprise. Chinese Academy of Agriculture Science, 10-11 (2007) 